\title{
TROPHIC CHARACTERISTICS OF Lymnaea stagnalis (MOLLUSCA: GASTROPODA: LYMNAEIDAE) IN TOXIC ENVIRONMENT
}

\author{
TETIANA PINKINA*, ANASTASIIA ZYMAROIEVA, SVITLANA MATKOVSKA, \\ MYKOLA SVITELSKYI, OKSANA ISHCHUK, MYKOLA FEDIUCHKA
}

Zhytomyr National Agroecological University, Stary Boulevard 7, Zhytomyr, 10008, Ukraine; e-mail: pinkinatv61@ gmail.com

*Author for correspondence

\begin{abstract}
Pinkina T., Zymaroieva A., Matkovska S., Svitelskyi M., Ishchuk O., Fediuchka M.: Trophic characteristics of Lymnaea stagnalis (Mollusca: Gastropoda: Lymnaeidae) in toxic environment. Ekológia (Bratislava), Vol. 38, No. 3, p. 292-300, 2019.

The influence of ions of heavy metals (copper, cadmium, nickel, zinc, cobalt and manganese) was investigated on the basis of trophic characteristics: the average daily ration (ADR), and duration of food passage (DFP) of the Lymnaea stagnalis L. in various concentrations of toxicants in vivisection experiment. In addition to these indicators, the total amount of food consumed in the solutions with various concentrations of pollutants was found out during the chronic experiment and it was calculated for an individual (average monthly ration - AMR). It leads to the conclusions about the intensity of food consuming considering different levels of intoxication. In solutions with lethal concentrations, the death of animals occurs during the first day of its impact due to the damage of tissues and organ systems. Chronic lethal concentrations of toxicants inhibit the nutrition of pond snails dramatically. At the beginning of the experiment, solutions of heavy metals with sublethal concentrations give some stimulatory effect on the digestive system of molluscs that is replaced by its suppression in case of longer being in the toxic environment. The influence of toxicants within a subthreshold limit cannot be considered safe because of the cumulative properties of heavy metals - they become sublethal with prolonged exposure time.
\end{abstract}

Key words: Lymnaea stagnalis $\mathrm{L} ., \mathrm{Cu}^{2+}, \mathrm{Cd}^{2+}, \mathrm{Ni}^{2+}, \mathrm{Zn}^{2+}, \mathrm{Co}^{2+}, \mathrm{Mn}^{2+}$, toxicity, trophic characteristics, molluscs.

\section{Introduction}

The circulation of substances in reservoirs is closely related to the nutrition of animals (Abi-Ayad et al., 2018). Hence, there is a need to study the mechanism and nature of hydrobionts' nutrition (Sushkina, 1949). Selective food consumption of the most common species of hydrobionts, Lymnaea stagnalis (Linné, 1758) including, was established (Rodina, 1957). E. Frömming (1953) expressed the number of leaves of semi-submerged and submerged plants eaten by pond snails in their area. Pondweed is eaten only during starvation, but dead and macerated parts are consumed quite willingly. The same happens to elodea. According to some researchers (Wiktor, 1958; Kunakh et al., 
2018), molluscs eat all the plants that are exposed to their radulae. There are other things except algae to feed molluscs, such as planktonic organisms, large invertebrates, plant detritus, animal corpses and feces. However, its favorite species are preferred if feed is sufficient and varied (Cihon-Lukanina, 1987; Yorkina et al., 2018). In laboratory conditions, pond snails eagerly eat carrots, cabbage, salad and dandelion leaves (Stroganov et al., 1977). The intensity of food consuming depends on its quality and quantity (Seifert, 1990), as well as on the physiological state of the organism. For example, a strong invasion of trematodes may increase it 81-93.6 times (Cihon-Lukanina, 1987). The average daily ration values the amount of food consumed, reflecting the ratio between the weight of feed taken in and the weight of a mollusc. The average daily ration depends on the age of the ponds (at a young age, it is 2.5 times that of the older individuals) (Stadnichenko, Kotsyuk, 1990) and on the temperature (young individuals react more slowly to changes in temperature in contrast to the old ones) (Sushkina, 1949). Laboratory studies have shown that the rate of eating does not increase after reaching maximum values with an increase in food quantity (Sushenia, 1975). Calculation of food consumed is carried out experimentally by means of analyzing the process of filling the digestive tract and the speed of food passing through it (Kerr, 1982).

Two ways of receiving inorganic ions constitute a distinctive physiological feature of hydrobionts' body. One of them is due to the absorption of ions directly from the water through the mucous membranes, and the other way is oral, connected with the passage of substances absorbed in the intestine to hepatopancreas (Romanenko, 1978). The nutrition process of herbivorous molluscs is characterized by intensity, regularity and labor intensity. During the nutrition process, a large mass of substratum is scraped off from the substrate, and only part of it is digested. Since plants are concentrators of heavy metal ions (Melchakov, 1989), it is possible to transfer heavy metals from the producers to further links (Morozov, 1983) in food chains, including phytophagous molluscs.

Particular attention should be paid to animals' nutrition in a toxic environment, as nutritive behavior (intensity or decrease in food consumption) may be the indicator of sensitivity to the effects of toxicants. At high concentrations of toxicants, there is always a suppression of nutrition. In sublethal concentrations, molluscs consume less nutrient during the first two weeks, and later more than it is normal (Stroganov et al., 1977). The reason for this is the need to withstand the pathological changes occurring in the animals' organism affected by toxicants (Pinkina, Pinkin, 2018). Therefore, establishing the main trophic parameters of L. stagnalis in the environment intoxicated by heavy metal ions is the purpose of our research.

\section{Material and methods}

As a material for comparative toxicological studies and for indicating the quality of water, any group of organisms can be used, large invertebrates among them are the most suitable research material. They are the most representative group in any reservoir, they do not need complicated equipment for extraction and microscopy and are relatively simple for systematization and experimentation. For toxicological experiments, gastropod pulmonary mollusks are very convenient objects (Bren, 1999; Zabory, 1986). The gastropod pond mollusc L. stagnalis L. was selected among them as the most common representative in the Central (Zhytomyr) Polissya. The choice of this object is determined by a small investment of time, labor and accordingly the cost of material resources for their collection, experiments and introduction into the system of hydromonitoring.

The same size pond snails (average height of the shell - $39.5 \pm 1.1 \mathrm{~mm}$ ) collected in the basin of the Middle Dniper River Teterev (Zhytomyr) served as the material for investigation. 2631 samples were used to study the peculiarities of molluscs' nutrition under the effects of toxicants; among them, 940 samples were used to determine the duration of food passing through the digestive tract, 1140 samples helped to determine the average daily ration and 551 items - to find out the average monthly ration. 
Experimental conditions: water temperature $-19-23^{\circ} \mathrm{C}, \mathrm{pH} 7.2-8.6$, oxygen content $8.6-8.9 \mathrm{mg} / \mathrm{dm}^{3}$. Toxicants $-\mathrm{Cu}^{2+}$, $\mathrm{Cd}^{2+}, \mathrm{Ni}^{2+}, \mathrm{Zn}^{2+}, \mathrm{Co}^{2+}, \mathrm{Mn}^{2+}$ in liquid substance. The solutions were prepared on dechlorinated (1 day) water from zhytomyr water supply system.

Young dandelion leaves served as a feed object in our experiments. This plant is often used in laboratory studies and is eagerly eaten by pond snails.

Toxicological experiments were delivered according to the methods by Alekseev (1981). Two preliminary experiments were held for every toxicant before the main investigation. In the first one, concentrations were determined in which $100 \%$ of animals die or remain alive. The range between lethal and inactive concentrations was chosen as the starting point for the main experiment, and the concentration of the toxicant, in which $100 \%$ of the animals died, was the concentration of the mother solution. In the second preliminary experiment, which was as long as the main one, the ranges of the sharp lethal, chronic lethal, sublethal and subthreshold concentrations were established. In the main experiment, 4 concentrations were used, one for each range of concentrations (Table 1).

$\mathrm{T} \mathrm{a} \mathrm{b}$ le 1 . Concentrations of heavy metal ions $\left(\mathrm{mg} / \mathrm{dm}^{3}\right)$ used in the experiments.

\begin{tabular}{|c|c|c|c|c|}
\hline \multirow{2}{*}{ Ions } & \multicolumn{4}{|c|}{ Concentrations } \\
\cline { 2 - 5 } & Sharp Lethal & Chronic Lethal & Sublethal & Subthreshold \\
\hline $\mathrm{Cu}^{2+}$ & 4 & 0,04 & $4 \cdot 10^{-5}$ & $4 \cdot 10^{-8}$ \\
\hline $\mathrm{Cd}^{2+}$ & 5 & 0,05 & $5 \cdot 10^{-4}$ & $5 \cdot 10^{-6}$ \\
\hline $\mathrm{Ni}^{2+}$ & 10 & 0,05 & $5 \cdot 10^{-3}$ & $5 \cdot 10^{-6}$ \\
\hline $\mathrm{Zn}^{2+}$ & 15 & 0,5 & $5 \cdot 10^{-3}$ & $5 \cdot 10^{-5}$ \\
\hline $\mathrm{Co}^{2+}$ & 25 & 2,5 & 0,25 & 0,03 \\
\hline $\mathrm{Mn}^{2+}$ & 110 & 30 & 0,3 & 0,03 \\
\hline
\end{tabular}

To determine the value of the average daily ration, the animals' shells were drained with filter paper, their total mass was determined and they were placed one by one in a separate tank filled with toxic stuff. The mollusks were immediately given feed preliminarily weighed on torsion weights (VLTK-500). The feed was placed between sheets of filter paper before weighing and kept under a weight of 1 kilo for 20 minutes. The duration of the experiment was 48 hours. At the end of the experiment, the remaining feed was drained to remove excessive moisture and weighed. By the difference in feed weight before and after the experiment, the amount of daily intake by each individual was determined. The value of the average daily ration - $\mathrm{ADR}$ (in \% relative to the raw mass of the body of the pond snails) was determined by the formula:

$$
X=(A .100) / P \text {, }
$$

where $\mathrm{X}$ is the value of the average daily ration; A - the mass of food consumed by a mollusk, $\mathrm{g}$; $\mathrm{P}$ - the total mass of his body, $\mathrm{g}$.

To determine the length of feed passage along the molluscs' digestive tract, they were fed with thin slices of macerated (6 days) in water carrots. They were then fed with the green (dandelion leaves). The time for the appearance of the first excrements containing the remains of this feed was set, calculating the difference between this time and the beginning of consumption of the green feed. This difference is the duration of feed passing through the digestive tract (DFP).

In addition to these indicators, the total amount of feed consumed by molluscs (TAFC) was determined in solutions of various toxic concentrations during the chronic experiment and it was recalculated per an individual. It made it possible to draw conclusions about the intensity of feed intake at different levels of intoxication.

The received digital data are processed using standard methods of variation statistics (Lakin, 1990) and special computer programs MS Excel and Statsoft Statistica 6.0.

\section{Results and discussion}

It is well-known that feed is the main organisms' "channel of communication" with the environment. All the major aspects of their life depend on it: the cost of exchange, somatic growth, maturation of sexual products and reproduction. Therefore, the explanation of the peculiarities of the pond snails' trophic in the environment containing heavy metal ions is of considerable interest. 
We investigated 3 main trophic indicators, namely: the average daily ration (ADR), the duration of feed passing (DFP) and the average monthly ration (AMR). ADR and DFP are the most important trophic characteristics for understanding the intensity of feed intake by the organism under different conditions and patterns of feed digestion and absorption of nutrients. Sushkina (1949) used these indicators in the study of trophic freshwater molluscs (L. stagnalis and Planorbarius corneus, Linne, 1758) for the first time. The functional relationship between the mollusc organism and its habitat concerning copper and zinc is partly studied (Vyskushenko, 2002). The values of ADR and DFP for Lymnaea palustris (O.F. Muller, 1774) under the influence of cadmium ions were determined by O.M. Vasilenko for the first time (Vasilenko, 2004). There is no data on the indicated trophic indices for L. stagnalis under the influence of nickel, cobalt and manganese ions, and the values of these indices have been established for the first time in this research, as well as the value of AMR for all six investigated metals, which indicate increasing or weakening of the trophic function of the pond snail in a long lasting poisonous environment.

The results of our research have proved that the average daily ration (Fig. 1) and the duration of feed passing through the digestive tract (Fig. 2) fluctuate within a rather significant range. The minimum and maximum values of these indicators are respectively: $1.55-2.73 \%$ and $350-440$ min under the effect of copper ions; $1.65-3.45 \%$ and $341-483 \mathrm{~min}$ - cadmium ions; $2.52-4.94 \%$ and 396-477 min - nickel ions; $1.05-2.92 \%$ and 338-467 min - zinc ions; $1.30-1.74 \%$ and $360-944$ min - cobalt ions and $2.18-4.65 \%$ and $302-423$ min under the effect of manganese ions. According to the results of experiments by Cihon-Lukanina (Cihon-Lukanina, 1987), the range of nutrition indicators for the pond snails is also quite large (sometimes up to $85 \%$ ).
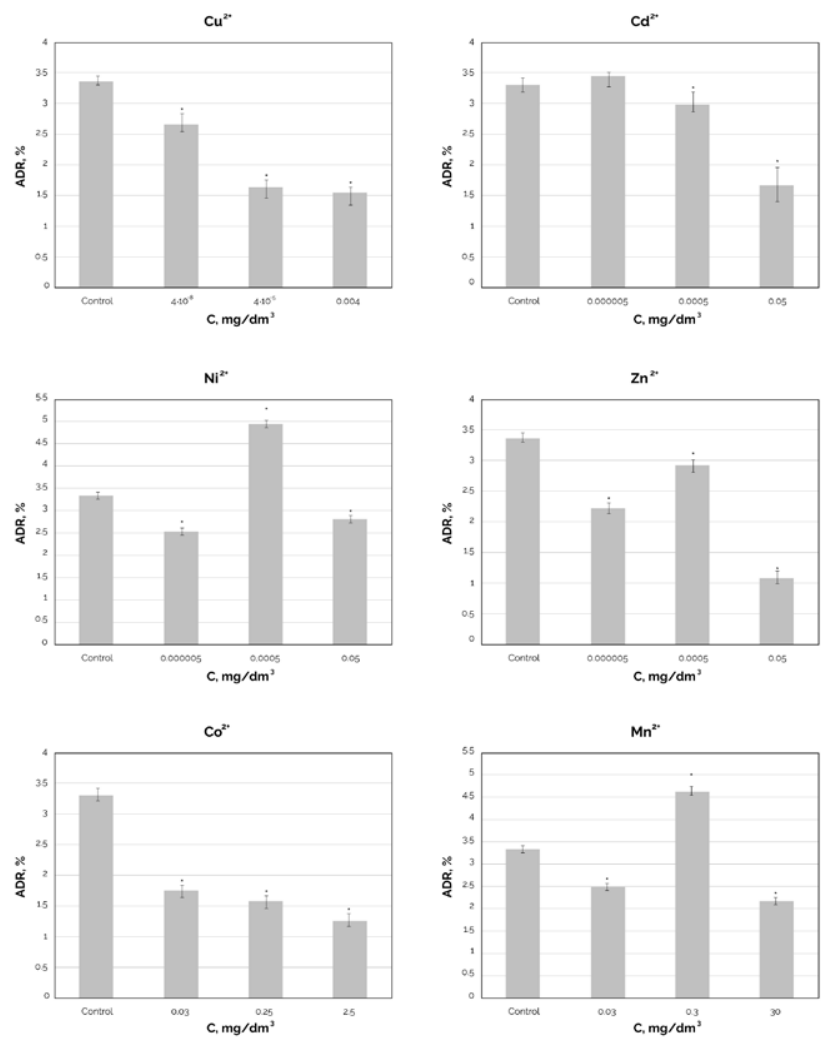

Fig. 1. The value of the average daily ration (\%) L. stagnalis under the effect of heavy metal ions $\left(\mathrm{Cu}^{2+}, \mathrm{Cd}^{2+}, \mathrm{Ni}^{2+}, \mathrm{Zn}^{2+}, \mathrm{Co}^{2+}, \mathrm{Mn}^{2}\right)$ in liquid substance; $\mathrm{x} \pm \mathrm{m}_{\mathrm{x}}$; $\mathrm{n}=6{ }^{*}-$ the differences compared with the control are probable. 

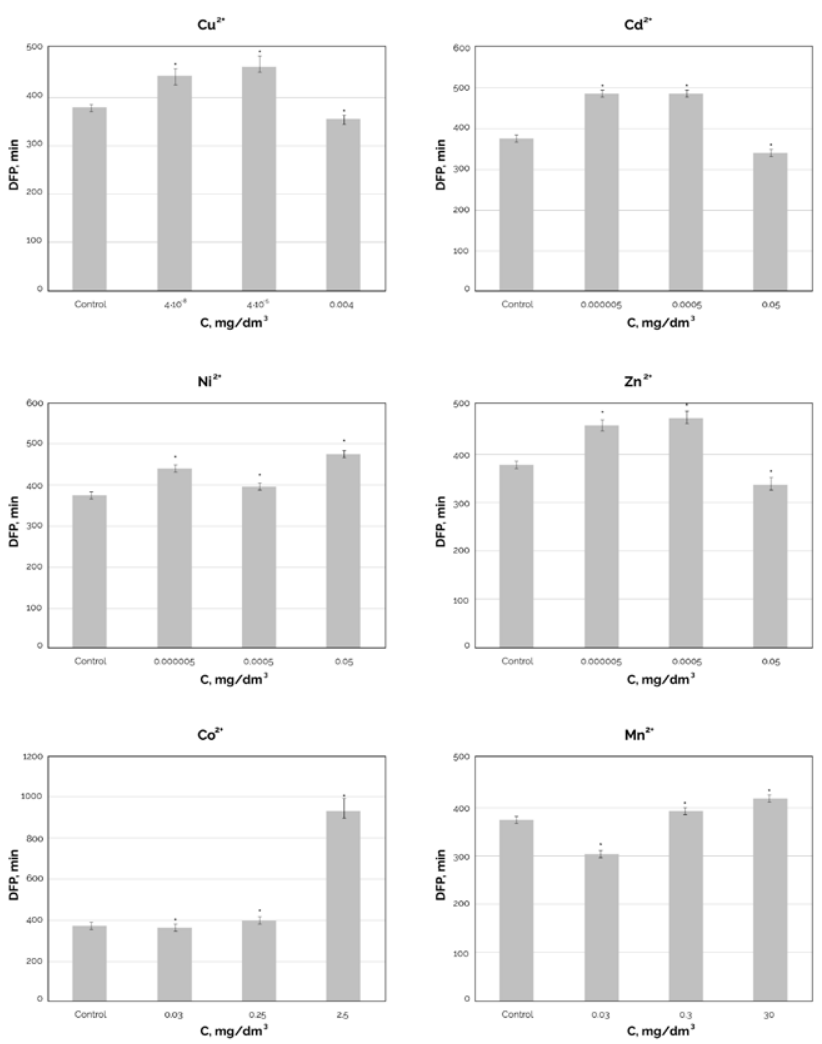

Fig. 2. Duration of feed passage ( $\mathrm{min}$ ) in L. stagnalis under the effect of heavy metal ions $\left(\mathrm{Cu}^{2+}, \mathrm{Cd}^{2+}, \mathrm{Ni}^{2+}, \mathrm{Zn}^{2+}, \mathrm{Co}^{2+}, \mathrm{Mn}^{2+}\right)$ in the liquid; $\mathrm{x} \pm \mathrm{m}_{\mathrm{x}} ; \mathrm{n}=$ $6 .{ }^{*}-$ the differences compared with the control are probable.
In studying the nutrition peculiarities of the pond snails, the same concentrations as in the main experiment were used, namely, in one of the range of chronic lethal, sublethal and subthreshold concentrations (Table 1). Research on molluscs' feeding in sharp lethal concentrations was not carried out. It is caused by preliminary observations, stating that animals in solutions of these concentrations almost or completely do not consume feed. Only some representatives (about $7-9 \%$ of the total number of molluscs) out of 40 pond snails found in solutions of sharp lethal concentrations showed sporadically weak consuming activity. The main functions of molluscs' organism in such concentrations are completely suppressed, the regulatory mechanism that compensates changes in the body doesn't perform its function, thus leading to the death of animals in the long run.

In general, pond snails' eating activity (in particular, their refusal of food) under the effect of heavy metals in liquid substance varies. Thus, in subthreshold concentrations, only some individuals if any, refuse food. In sublethal concentrations, $7-10 \%$ out of the total number of molluscs follow this tendency. Up to $30 \%$ of animals almost do not consume food in solutions with chronic lethal concentrations.

Only at a concentration of $0.04 \mathrm{mg} / \mathrm{dm}^{3}$, the decrease in the amount of food consumed as well as in the duration of its passage $(\mathrm{P}<0.05)$ is observed. It indicates an increase in the toxic effects of copper at this concentration, which manifests itself in the suppression of digestive processes. The fact, that molluscs are sensitive even to the subthreshold non-active (according to other indicators of the investigated pollutant and animal ethology) concentrations, demonstrates a strong toxic effect of copper on the pond snails even at very low $\left(4 \cdot 10^{-8} \mathrm{mg} / \mathrm{dm}^{3}\right)$ concentrations.

The amount of daily consumed feed increases slightly, while the duration of food passage increases 1.3 times under the effect of ions of cadmium on molluscs at the concentration of $5 \cdot 10^{-6}$ 
$\mathrm{mg} / \mathrm{dm}^{3}$. As the toxicant concentration increases, ADR decreases (Fig. 1). DFP indices are significantly increased at concentrations of $5 \cdot 10^{-4}$ $\mathrm{mg} / \mathrm{dm}^{3}$, activating animals' metabolism to a certain extent, moreover DFP indices decrease considerably with increasing concentration of cadmium ions in the environment (Fig. 2). Consequently, molluscs are no longer able to withstand the pathogenic effects of the pollutant at concentrations of $0.05 \mathrm{mg} / \mathrm{dm}^{3}$.

The information above corresponds to the data obtained by Vasilenko (2004), although the scientist demonstrated a larger range of the variations in the values of pond snails' ADR and DFP in solutions of cadmium ions. It can be explained by the difference in feed used in the experiments.

The same concentrations as in the study of the influence of cadmium ions (according to the results of the previous ecotoxicological researches, these metals belong to one toxicological group) are used in the analysis of the effect of nickel ions on the peculiarities of the pond snails' feeding. A different dynamic of changes in nutrition indicators is observed in this experiment. ADR decreases in 1.3 times and DFP increases almost as many times at concentrations of $5 \cdot 10^{-6} \mathrm{mg} / \mathrm{dm}^{3}$ of nickel ions in the substance. There is a contrasting tendency at sublethal concentrations $(0.005$ $\mathrm{mg} / \mathrm{dm}^{3}$ ): the ADR value increases by 1.5 times, while the passage of food along the digestive tract is slowing down (Figs 1,2). Feed consumption decreases again in solutions with higher concentrations of $\mathrm{Ni}^{2+}\left(0.05 \mathrm{mg} / \mathrm{dm}^{3}\right)$, indicating a strong depression of molluscs' digestive processes.

The value of DFP increases in solutions with nickel ions in response to the decrease in ADR, and although the animals are still able to withstand the influence of toxicants for a while, it is evident that their further presence in poisonous water will lead to the death of individuals.

The same pattern in reaction of the digestive system to the influence of the toxicant is observed as in the substance containing copper, cadmium and nickel ions if pond snails are in solutions with 
different concentrations of zinc ions. As the concentration of this toxicant increases, there is a decrease in the ADR values (Fig. 1). DFP values increase initially in response to it, compensating toxic effects to some extent, and then, they are greatly reduced with the development of the depressive phase of the general pathological process of intoxication, which is accompanied with the suppression of the protective and adaptive properties of these animals (Fig. 2).

Considering the change in DFP at different concentrations of zinc ions in water, it can be stated that the growth of its values in solutions of $5 \cdot 10^{-5} \mathrm{mg} / \mathrm{dm}^{3}$ and $5 \cdot 10^{-3} \mathrm{mg} / \mathrm{dm}^{3}$ can compensate the progressive fall of ADR of the molluscs under investigation only partly.

It was established that the value of $\mathrm{ADR}$ also decreases with increasing concentrations in solutions with cobalt ions (Fig. 1). The value of DFP grows rather slowly first with an increase in the concentration of toxicants and it gets higher than control by only $5.8 \%$ at the concentration of 0.25 $\mathrm{mg} / \mathrm{dm}^{3}$. The increase in the value of the investigated indicator continues at $2.5 \mathrm{mg} / \mathrm{dm}^{3}$ of this ion in the substance, increasing by $151.6 \%$ (in 2.5 times) in terms of control (Fig. 2). It shows an extremely strong damage to the digestive system of the pond snail caused by high concentrations of ions of cobalt, which leads to almost complete paralysis of the intestines and ceasing of its peristaltic activity. Most animals generally refuse to consume feed in these solutions.

The change in the nutritional indices under the influence of manganese ions in water is similar to the effect of other investigated metals: there is a tendency to decrease ADR and increase DFP with the increase in the concentration of toxicant in the environment (Figs 1,2) (Pinkina, Pinkin, 2018). These indices bear statistically significant difference to the control $(\mathrm{P}<0.05)$ at all investigated concentrations of manganese ions.

Taking into account the cumulative properties of heavy metal ions, the values of the average monthly ration of molluscs (in terms of one person) were calculated, making it possible to more specifically talk about ruining the digestive processes of these animals. As a result of these studies, it was found that the amount of feed consumed by pond snails is progressively decreasing with an increase in the concentration of toxicants. The same pattern is established during the 48-hour exposition. However, the results of the chronic experiment show a sharper decrease in the amount of feed consumed with an increase in the concentration of metal ions in the medium (Fig. 3). It can be explained by the increase in the toxic effects of the indicated pollutants due to their accumulation in the body of molluscs.

The lack of statistically significant difference compared to control in solutions with copper ion concentration by $4 \cdot 10^{-5}$ and $4 \cdot 10^{-8} \mathrm{mg} / \mathrm{dm}^{3}$ (Fig. 3) in the acute experiment (Fig. 1) indicates that animals submerged into a toxic environment, react more sharply on it initially. Adaptation mechanisms appear in some time, so the amount of feed consumed decreases insignificantly regarding control.

The amount of average monthly food consumed by an individual feeder at low concentrations coincides with it in the control and it is equal to $0.33 \pm 0.03 \mathrm{~g}$ in solutions with cadmium ions. As the toxicant concentration increases, the amount of feed consumed decreases gradually $(\mathrm{P}<0.05)$. The dynamics of changes in the investigated value is very similar to the same in solutions of copper ions.

The digestive system of molluscs is quite sensitive to the effects of nickel ions. If there is a slight stimulation of this function in the concentration of $5 \cdot 10^{-4} \mathrm{mg} / \mathrm{dm}^{3}$ and consumption of food falls 1.5 times compared with control, then feed is reduced by half $(\mathrm{P}<0.05)$ at lower $\left(5 \cdot 10^{-6} \mathrm{mg} / \mathrm{dm}^{3}\right)$ and higher $\left(0.05 \mathrm{mg} / \mathrm{dm}^{3}\right)$ concentrations of this pollutant in the nutrition environment. 
There is a pronounced depression of pond snails' trophic processes under the influence of cobalt ions at the concentration of the specified toxicant going high. At the concentration of 0.03 $\mathrm{mg} / \mathrm{dm}^{3}$, which molluscs do not react to with changes in ethology and other physiological systems at all, consumption of food is reduced by 2.5 times, and at the concentration of $2.5 \mathrm{mg} / \mathrm{dm}^{3}$ even by 4 times (Fig. 3). Similar data were obtained even during the 48-hour experiment.

Since the trematode invasion complicates the course of the pathological process caused by the poisoning of molluscs with toxicants, the trophological indices of the pond snails infected with rediae and cercariae of the echinostomatitis trematodes (the family Echinostomatidae) were singled out from the general data obtained.

The results obtained in this research point to the importance of analyzing the trophic indices of animals in toxicological studies, since they clearly highlight the general physiological state of individuals that are in a toxic environment. According to the nutrition indicators, pond snails are quite sensitive to the influence of heavy metal ions.

In response to a decrease in feed intake, the body of the pond snail reacts with an increase in the time of finding food in the digestive tract of the mollusc. Such adaptation to the pathogenic influence of heavy metals only partially compensates for their negative effects, and at higher concentrations, pathological processes begin to prevail over protective and adaptive, which leads to a decrease in both ADR and DFP along the digestive tract of molluscs. Trophic indicators of pond snails are most sensitive to the effect of nickel and cobalt ions, and it differs from the overall toxicity of these substances, which is determined by the survival of individuals. Obviously, heavy metals having a general toxic effect on organisms, can have a specific (stronger or weaker) effect on certain functional systems. Such features can be used as test-reactions in the system of biomonitoring of the quality of natural water.

\section{Conclusion}

The results of our studies given above prove that the food consumption is sensitive enough to reflect the changes in the intensity and direction of $L$. stagnalis metabolic processes. It allows us to use the employed indicators as signs of the normal functional state of the organism and the functional state under the effect of extreme stimuli of chemical nature, including toxic substances.

Depression of nutrition and, consequently, strong growth retardation of animals are observed due to chronic lethal concentrations of pollutants. Under these conditions, pathological processes predominate over protective and adaptive ones, leading to a decrease in the average daily and average monthly rations and the duration of feed passing along the digestive tract. under the effect of sublethal concentrations of heavy metals. The reduction of feed intake is accompanied by lengthening of the time of feed remaining in the molluscs' digestive tract. Pond snails are most sensitive to the action of $\mathrm{Ni}^{2+}$ and $\mathrm{Co}^{2+}$ considering trophic indexes.

In most cases, animals infected with parthenitae and larvae of the trematodes undergo the toxicant effect faster than the uninfected representatives.

Adaptation to the action of heavy metal ions is relative, since large energy costs are compensated only partially, and in the end, it leads to a shortage of macroergic substances in the animal's body. Consequently, energy imbalance becomes one of the causes of death of animals in the toxic environment. 


\section{References}

Abi-Ayad, L., Ghezlaoui, S.-M. B.-D., Belkhouche, N. \& Aguado J.M. (2018). Spatiotemporal bioaccumulation of lead, cadmium, zinc and copper metals in Lettuce Sea Ulva lactuca harvest in two Algerian west coasts. Ekológia (Bratislava), 37(3), 243-258. DOI: 10.2478/eko-2018-0020.

Alekseev, V.A. (1981). Basic principles of the comparative-toxicological experiment (in Russian). Hydrobiological Journal, 17(3), 92-100.

Bren, N.V. (1999). Use of invertebrates to monitor pollution of aquatic ecosystems by heavy metals (in Russian). Hydrobiological Journal, 35(4), 75-88.

Cihon-Lukanina, E.A. (1987). Trophology of aquatic molluscs (in Russian). Moscow: Nauka.

Frömming, E. (1953). Quantitative studies on food intake of freshwater pulmonata snail Lymnaea stagnalis L. Fisheries, 2(5-6), 451-456.

Kerr, S.R. (1982). Estimating the energy budget of actively predatory fishes. Can. J. Fish. Aquat. Sci., 39(3), 371-379. DOI: $10.1139 / \mathrm{f} 82-054$.

Kunakh, O.N., Kramarenko, S.S., Zhukov, A.V., Kramarenko, A.S. \& Yorkina N.V. (2018). Fitting competing models and evaluation model parameters of the abundance distribution of the land snail Vallonia pulchella (Pulmonata, Valloniidae). Regulatory Mechanisms in Biosystems, 9(2), 198-202. DOI: 10.15421/021829.

Lakin, G.V. (1990). Biometrics (in Russian). Moskow: Vysshaya Shkila.

Melchakov, Yu.L. (1989). Correlation of atmospheric and water migration with the biological cycle of heavy metals in the mountain-forest landscape (in Russian). Biological Science, 9, 28-32.

Morozov, N.P. (1983). Chemical elements in hydrobionts and food chains. Biogeochemistry of the ocean (in Russian) (pp. 127-165). Moscow: Nauka.

Pinkina, T.V. \& Pinkin A.A. (2018). Analysis of the toxic resistance of the pond snail (Mollusca: Gastropoda) to the influence of manganium ions (II) in an aquatic environment (in Ukrainian). Ukrainian Journal of Ecology, 8(1), 719-729. DOI: 10.15421/2018_272.

Rodina, A.G. (1957). The possibility of using the method of labeled atoms to solve the problem of food selectivity of aquatic animals (in Russian). Zoology Journal, 36(3), 337-343.

Romanenko, V.D. (1978). Liver and regulation of interstitial metabolism (mammals and fish) (in Russian). Kyiv: Naukova dumka.

Seifert, D.V. (1990). Quantitative aspects of terrestrial molluscs' nutrition. Power of nutrition and growth of animals (in Russian) (pp. 105-130). Sverdlovsk: USC of the USSR Academy of Sciences.

Stadnichenko, A.P. \& Kotsyuk R.V. (1990). The effects of different concentrations of surfactants on the value of the daily rations and duration of food passage in Lymnaea stagnalis infected with Echinostoma revolutum Parthenitae (in Russian). Parasitology, 6, 528-532.

Stroganov, N.S., Danilchenko, O.P. \& Amochaev E.I. (1977). Change in plastic exchange of molluscs Lymnaea stagnalis under the influence of tributyltinchloride in low concentrations (in Russian). Biological Science, 4, 75-78.

Sushenia, L.M. (1975). Quantitative patterns of feeding crustaceans (in Russian). Minsk: Science and Technology.

Sushkina, A.P. (1949). Nutrition and growth of some gastropods (in Russian). Tr. Soviet Union of Hydrobiological Society, 1, 118-131.

Vasilenko, O.M. (2004). Ions of heavy metals in the ration of Lymnaea palustris (Mollusca, Pulmonata) (in Ukrainian). Bulletin of DAU: Scientific and Theoretical Collection, 2, 284-287.

Vyskushenko, D.A. (2002). Reaction of the pond snail (Lymnaea stagnalis L.) to the effect of copper sulfate and zinc chloride (in Russian). Hydrobiological Journal, 38(4), 86-92.

Wiktor, A. (1958). From the biology of snails' nutrition. Przeglad Zoologiczny, 2(2), 125-146.

Yorkina, N., Maslikova, K., Kunah, O. \& Zhukov O. (2018). Analysis of the spatial organization of Vallonia pulchella (Muller, 1774) ecological niche in Technosols (Nikopol manganese ore basin, Ukraine). Ecologica Montenegrina, 17, 29-45.

Zabory, L. (1986). Biomonitoring of heavy metals with the help of molluscs. Verhandlungen der Gesellschaften für Ökologie, 16. 